\title{
Parental Attitude towards Disability and Gender in the Nigerian Context: Implications for Conselling
}

\author{
Omoniyi, Mary Banke lyabo (Ph.D) \\ Department of Guidance and Counselling, Faculty of Education, Adekunle Ajasin \\ University, Akungba Akoko, Ondo State Nigerian \\ Email: zioncan25@yahoo.co.uk
}

\section{Doi:10.5901/mjss.2014.v5n20p2255}

\section{Abstract}

The study was undertaken to investigate the attitudes of parents towards their children gender and handicap conditions. The purposive, stratified sampling technique was adopted. The samples comprised of 60 parents (30 Fathers and 30 Mothers). A 35 item Parental Attitude Scale Instrument constructed by the researcher was used to assess information from the respondents. The instrument possess a high face and content validity and a test-re-test reliability coefficient of 0.96 . The results revealed significant differences related to gender of the children on various domains of the scale: There is a significant difference between the fathers and mothers' attitudes with father exhibiting more favourable attitudes towards male children. Mothers attitudes were also significant on the domain of over protection and acceptance. Counselling focused specifically towards developing healthy parental attitudes which would in turn result in acceptance of the child disability irrespective of gender were offered. The importance of strengthening the social support network of these children's families was also reiterated.

Keywords: Parental attitude, gender, disability.

\section{Introduction}

Cursory observations of the earliest writings of Man-Chinese, Egyptian, Hebrew and Greek- provide striking case histories of disturbed individuals and attitudes of their people towards them. In the history of the Athenian and Spartan city states for example reports were made of how they have dealt severely with handicapped children because their interest was in developing a society free of defectives. Handicapped children where thought of as essentially non-human and were treated accordingly. According to Kanner (1994), it was customary in Rome for the elite to keep those they referred to as "fools" and "jester" for the amusement of the household and its guests. He further reported that many owners of handicapped persons, particularly mentally retarded children, acquired greatness and fame as a result of their possessions. He reiterated that all such children did not fare well, as chains, cages or sentences of death were the fate of many, while others were left alone to roam and care for themselves and eventually died.

Evidence abounds to support the fact that prejudice against the handicapped is almost universal in Nigeria and affects their social, economic, educational, mental and psychological well being. From the days of Aristotle who equated deafness to mental incapacity to the present day, the handicapped seems to have had to fight more or less a losing battle in many countries (especially in the developing ones) to be conceded, the right to life as human beings. In certain communities in Nigeria, traditional attitudes are so negative towards the handicapped children that they are not even considered acceptable gifts to the gods. They are seen as "a taboo", an embarrassing spectacle and a disgrace to their families. Many handicapped children are still abandoned on streets and in bushes because they are considered as liabilities and a source of shame.

Marriages with members of families with handicapped children are also unthinkable in some communities. In our country, beliefs about the causes of disabilities tend to condition attitudes and reactions towards the exceptional child. Handicapping conditions such as deafness, blindness, mental retardation, orthopaedic impairment to mention but a few in traditional settings are mostly attributed to punishment by vengeful gods for wrong done in the present or past incarnations including; infidelity of parents, wanton murder, eating prohibited foods, fishing in sacred waters and even heedlessness on the part of the expectant mothers who expose certain parts of their bodies or walk in the noon day or in the dark at odd hours. In most rural communities, there is also a strong belief in witchcraft, evil spirits and demons who parade the streets at night causing havocs in form of disabilities to those who ignore their warnings. It is necessary however to emphasize that owing to the rapid diffusion of learning and civilization, there is a significant reduction in these 
die-hard negative attitudes towards the handicapped, even though traditional beliefs and attitudes towards the handicapped still differ from community to community depending on the nature of beliefs that provide a basis for the attitudes.

Children are the perfect extension of a couple's love, caring and the emotional preparation for expectant parents is usually shaped by glamorous image of the baby, a kind of ego ideal. The discrepancy between the perfect child of their fantasy and the real child may cause negative attitudes and parenting stress. Often a range of emotions, such as denial, guilt, blame, frustration, anger and despair, may sweep through the parents as they are confronted by their children with disability. Loss of hope for the 'perfect child' may cause grief and over time the feeling may be heightened by loneliness, isolation, and exhaustion. Parents may over-protect their child and feel guilty that they are responsible for the child's disability. The parents of children with disabilities may develop 'chronic sorrow' characterized by periodic recurrence of sadness, guilt, shock and pain. They may be plagued by feelings of pessimism; hostility and shame, denial, projection of blame, guilt, grief, withdrawal, rejection and acceptance (Drew, 2008). Some parents also experience helplessness, feelings of inadequacy, anger, shock and guilt, whereas others go through periods of disbelief, depression and selfblame. The siblings also experience feelings of guilt, shame and embarrassment (Frude, 2002).

Special education or special needs education is the practice of educating students with special_needs in a way that addresses their individual differences and needs. Ideally, this process involves the individually planne- and systematically monitored arrangement of teaching procedures, adapted equipment and materials, accessible settings and other interventions designed to help learners with special needs achieve a higher level of personal self-sufficiency and success in school and community than would be available if the student were only given access to a typical classroom education. Common special needs include learning disabilities, communication disabilities, emotional and behavioral disorders, physical disabilities and developmental disabilities. Students with these kinds of special needs are likely to benefit from additional educational services as different approaches to teaching, the use of technology, a specifically adapted teaching area, or a resources room.

The Nigerian Education Research Council (NERC), in 1977 provided the nation with a relevant definition of special education. According to the council, special education has been defined as an area with the framework of general education that provides appropriate training for all types of children within the nation's education system who have unusual needs. The Federal Government in the National Policy on Education (2004) also defined special education in its broadest terms thus: "Special Education is education of children and adult who have learning difficulty because of different sorts of handicaps; blindness, partial sightedness, deafness, hardness of hearing, mental retardation, social maladjustment, physical handicap, e.t.c. due to circumstances of birth, inheritance social position, mental and physical health or accident in later life".

In recent years, the need for special education has been recognized and accorded a place in the National Policy on education. Most special educators have realized that for handicapped children to become self-supporting individual in the community, they must be supervised and educated to the limits of their educational abilities. Awareness is being created in both the home and the schools now than ever before to make the handicapped child feel more secure; that he is part of the group rather than apart from them. Special education may help to discover the potentialities of each child regardless of the degree of the handicap. These potentialities are developed for the personal benefit of the individual and the society of which he is a part. The need for special education is to supply full measure of wholesome growth for each handicapped child, with due regard for the child's abilities and limitations and his possible contribution to society. It is a unique privilege for the special class teachers to guide, direct and encouraged optimum balance of physical, mental, emotional, spiritual and social development of the child who is handicapped.

\section{Statement of the Problem}

In today's society, individuals ability, competence and education level are what most people use to determine success. It is often assumed that one must have something to call his or her own to succeed and to gain respect, whether it is an opinion, a piece of land, an education degree or children. This is especially true for the Nigerian in regards to having children and an education. Bearing respectful, healthy and "normal" children is expected of most parents. Many times when children are handicapped unable to perform a task after many attempts, children and parents get frustrated and standards for children subsequent become lower. Children with disabilities, however, are automatically given lower standards than those without disabilities. The fact that disability and parental attitude are important dimensions along which discrimination occur may be particularly marked in the case of the education of girls having some form of disability. 


\section{Purpose}

The purpose of this study is to explore parental attitudes towards children with disabilities, their education and gender discrimination. Counseling interventions and coping strategies for parents of the disabled would also be highlighted

\section{Method}

The sample comprised of 60 parents (30 Fathers and 30 Mothers) of children with disabilities who attend a child and adolescent handicap centre of a Non-Governmental Organization in South West Nigeria. A purposive, stratified sampling technique was adopted in selecting the participants. Respondents were selected using the following criteria: (i) spouse should be alive( ii )Neither of the parent of the child should be a step parent (iii) Child should have stayed with parents since birth.

\section{Instrument}

Parents' attitudes towards their children disability and gender were assessed through the administration of a 35 item Parental Attitude Scale constructed by the researcher. 25 items were spread equally over 5 areas, namely: acceptance, rejection, over-protection permissiveness educational and the bio-data of the parents. The other 10 items consist of general categorical statements to which parents were requested to answer 'Yes' or 'No'.

The instrument has good face and content validity as confirmed by other colleagues in the department of counseling psychology and a high test-re-test reliability value of 0.96 and is found to be a highly valid tool in measuring the parental attitudes towards their children disability and education.

Parents were oriented about the purpose and confidentiality of the study before administering the questionnaire and consent was obtained. Parents were individually administered the questionnaire.

\section{Results}

Table 1: The mean scores of attitudes of parents towards their children disability.

\begin{tabular}{|l|c|c|c|c|}
\hline Domain of Attitude & Gender & Father & Mother & T-value \\
\hline \multirow{2}{*}{ Over Protection } & Boys & $5.53(2.52)$ & $6.17(2.13)$ & 2.990 \\
& Girls & $6.23(2.36)$ & $5.93(2.32)$ & 0.994 \\
\hline \multirow{2}{*}{ Permissiveness } & Boys & $7.20(2.07)$ & $7.47(2.75)$ & 0.868 \\
& Girls & $6.77(2.30)$ & $6.70(2.37)$ & 0.232 \\
\hline \multirow{2}{*}{ Acceptance } & Boys & $3.27(1.74)$ & $2.67(1.90)$ & 2.555 \\
& Girls & $2.00(1.17)$ & $2.13(1.59)$ & 0.730 \\
\hline \multirow{2}{*}{ Rejection } & Boys & $1.60(2.50)$ & $1.10(1.75)$ & 1.824 \\
& Girls & $0.90(1.37)$ & $0.47(5.43)$ & 0.980 \\
\hline \multirow{2}{*}{ Education } & Boys & $3.67(3.37)$ & $3.70(1.26)$ & 0.100 \\
& Girls & $2.68(1.52)$ & $2.90(1.35)$ & 1.188 \\
\hline \multirow{2}{*}{ Overall } & Boys & $36.53(8.67)$ & $36.13(7.38)$ & 0.386 \\
& Girls & $29.93(8.69)$ & $29.87(5.75)$ & 0.064 \\
\hline
\end{tabular}

Table 1 shows mothers attitudes towards boys were significant on the domain of over protection and Acceptance $(P<0.5)$.

Table 2: Attitudes of Fathers and Mothers

\begin{tabular}{|c|c|c|c|}
\hline Parents & Mean & Sd & T-value \\
\hline Father & 26.2 & 3.25 & \multirow{2}{*}{1.77} \\
\hline Mother & 24.7 & 3.32 & \\
\hline
\end{tabular}

Table 2: Indicates, means score of father at 26.2, and is higher than that of mothers (24.7). It can be inferred that fathers exhibit more favourable attitudes towards their handicapped children in comparison with mothers. It is further established that the difference in means between attitudes of mothers and fathers is significant at $(P<0.5)$

This finding could be attributed to the mother's expectation of an ideal child, and may also be a reflection of the 
mother's mourning for the lost "ideal" child. Another could be since child care in the Nigeria context almost exclusively rests on mothers, the intensive contact could in fact be leading to maternal burn-out or fatigue, and this could in turn probably lead to unfavourable attitudes towards the child. Another reason is that, the average Nigeria mother is more emotionally dependent on her child as compared to the father and her disappointment with a disabled child may be more.

Table3: Parental attitudes towards male and female children.

\begin{tabular}{|c|c|c|c|}
\hline Child & Mean & Sd & T-values \\
\cline { 1 - 2 } Male $(\mathrm{n}=36)$ & 26.16 & 3.04 & \multirow{2}{*}{2.44} \\
\hline Female $(\mathrm{n}=24)$ & 23.95 & 3.96 & \\
\hline
\end{tabular}

Table 3: shows the mean score of parental attitude for male is 26.16 and for female children is 23.95 , which suggests that parent's exhibit more favourable attitudes towards male children in comparison to female children. However, the obtained t-value 2.44 is not statistically significant.

Table 4: Fathers attitudes towards male and female children.

\begin{tabular}{|c|c|c|c|}
\hline Child & Mean & Sd & T-values \\
\hline Male $(n=17)$ & 27.33 & 2.48 & \multirow{2}{*}{2.11} \\
\hline Female $(n=13)$ & 24.84 & 3.71 & \\
\hline
\end{tabular}

As table 4: shows mean score for male children is higher than that for female children, that is father exhibit more favourable attitudes towards male children in comparison with female children. The obtained t-value is statistically significant at $\mathrm{P}<.05$ level. The differential preference may well be a reflection of the cultural bias favouring male children.

Table 5: Attitudes of mothers towards male and female children.

\begin{tabular}{|c|c|c|c|}
\hline Child & Mean & Sd & T-values \\
\hline Male $(n=19)$ & 25.31 & 3.18 & \multirow{2}{*}{1.35} \\
\hline Female $(n=13)$ & 23.63 & 3.43 & \\
\hline
\end{tabular}

Table5 depicts the attitudes of mothers towards their male and female disabled children. The mean score of mothers towards male children is somewhat higher than the mean score of female children. The obtained t-value is not significant at $\mathrm{P}<.05$.

Table 6: Education levels of parents and parental attitudes

\begin{tabular}{|l|c|c|}
\hline Educational Level & Number & Mean \\
\hline Pry 6/ School Certificate & 27 & 24.29 \\
\hline OND/NCE & 20 & 26.15 \\
\hline Graduate and Above & 13 & 26.76 \\
\hline
\end{tabular}

Analysis of variance was applied to analyze the difference in parental attitudes for three different education levels. Table 6 indicates that there is a significant difference among the different educational levels at $P<.05$. It may be inferred that as the education level of parents increases, the attitudes towards their handicapped children becomes more favourable.

The difference between attitudes of parents with Primary Six / School Certificate education level and those of graduate parents / other higher educational qualifications is significant at $\mathrm{P}<.05$. Similar trend is reported by Kurian, (2008) who reports a significant difference in parental attitudes between the lowest and higher socio-economics groups. One possible reason could be that more educated people are more likely to be able to acquire greater levels of information about disability, rehabilitation measures and resources and can access the latest medical and rehabilitation help available. 


\section{Discussion}

The aim of the current study was to assess parental attitudes towards their children gender and disability. The results clearly showed differences in parental perceptions related to the gender of these children. The reason could be that parents expect more from male children than female children. Boys are expected to achieve higher level in education, hold better positions and be financially secure in the cultural context in the country. This indicates parents, willingness to educate boys as compared to girls. The findings of the current study are in concurrence with many other studies. Overprotection (Perosa, 1982) and rejection (Minuchi, 1978; Nbuzoka and Smith, 2003) are the common parental attitudes towards children with disability. These parents were initially ignorant about the extent of their child disability. Later, they reported feeling anxiety, guilt, insecurity, emotional instability, self-pity and hopelessness. Every parent dreams about his/her child being 'perfect' in all respects. When there is disability in spite of above-average intelligence, the disappointed parents develop negative attitudes towards the child. Some of them become over-protective and fail to make realistic demands on the child. The family needs psycho-educational inputs to encourage them to equally educate the disabled girl child.

When asked what it is like to be the parent of a child or young adult with a disability, these parents described a life of hard work, exhaustion, fear, hope, despair, anger, isolation, intimidation, commitment acceptance and love. Some parents felt abandoned and isolated while some acknowledge the support provided by Non-Governmental Organizations (NGOs) and their own immediate families. They were tired of having to 'Push' for everything their child needs. Although many of the parents were still relatively young people, the fear of what will happen to their children when they die seems to pervade their lives. Most of the parents were also concerned about the quality of the children's life such as being able to meet friends and peers and to pursue activities they wish. However, they lamented that without parental support, this would not be possible.

\section{Implications for Counselling}

The right for all people to be included as equal citizens is recognized by the Nigeria Government. However, the society has persistently discriminated and violates the rights of persons with disabilities. A special focus was placed on the rights for persons with disabilities after the UN's year for disabled in 1981. The main strategy has been to secure the legal rights to "full participation and equality" not by passing separate laws for persons with disabilities, but by including rights and obligations for persons with disabilities in the laws that apply to all citizens. This includes the democratic right to be represented when decisions are made in matters that have a consequence for persons with disabilities. Nigeria Government is yet to fulfill this practically in our society. The Nigeria constitution has not recognized the legal rights of persons with disabilities. Even though the right to education for children with disabilities became a reality through the establishment $n$ of special schools and training of special teachers, the financial implications for their training and care are still left in the hands of their parents without any social support. In most African countries, disabilities is still viewed in terms of "tragedy" with a "better dead than disabled" approach; the idea being that it is not possible for people with disability to be happy or enjoy a good quality of life. Cultural belief about disability plays an important role in determining the way in which the family perceives disability and the kind of measures it takes for prevention, treatment and rehabilitation. Helping families to develop a positive outlook might be the serving point of intervention by counseling professionals. There is a need to develop culturally appropriate intervention strategies to help the families and children to adapt to the situation. Most often the intervention may be done at the level of the child addressing the disability parse. Professional counselors while working with families should strengthen the social network and support systems, which would help them, overcome the stress and negative attitude towards their children with disability. Research has found a strong association between supportive social networks and the positive psychological well-being of parents of children with disabilities (McGaw, 2002; Kroese, 2008). It is found that most parents generally lack opportunities to share their experiences and gain support from friends and even extended family members. Within support groups and group counseling sessions, they can discuss pertinent emotional issues, such as feelings of frustration and child-rearing problems. It is also an effectives forum to help parents develop realistic expectations for the child and to engender feelings of competence.

Such network support group may help families in gaining confidence, improving self-esteem and assertiveness, and enhancing feelings of control. These groups can act as a social support network, which is often missing from the lives of parents of children with disabilities. Improved confidence and sense of well-being engendered by an increased sense of self-worth among these parents may positively affect parenting and bring attitudinal changes towards children with disabilities and gender discrimination. In Nigeria, this kind of network supporting system is often lacking. Non- 
Governmental Organizations can play an important role in forming such social support groups for parents of children with disability. Expanding social networks can therefore be an important part of a "family-centered" approach to support such parents.

Individual counseling sessions may also take place in designate centers in communities where parents concerns are individually carefully assessed and interpreted. Counseling professionals can then make appropriate decisions as to how each family can be helped, based on their identified needs. It is also counseled that the general negative traditional attitudes and beliefs towards children with disabilities be eradicated from our society. Education of the masses on the characteristic and needs of children with disabilities in the social activities of their communities, including sporting activities, drama and cultural displays may help. Television and radio programmes featuring probable causes of congenital and acquired disabilities may go a long way to enlighten the minds of people advocating causative agents of disabilities in children to witches or ancestral gods. Nigeria Governments are also counseled to enact legislative measures to guarantee the rights of children with disabilities like we have in more advance countries of the world. Moreover, public utilities should be built in a way that the disabled children and adults are put into consideration.

\section{Conclusion}

Parents exhibit more favourable attitudes towards their handicapped sons than towards their daughters. As education levels improve, parental attitude also become more favourable. Since parental attitudes play an important role in education and rehabilitation of any disabled child, it may be desirable to adopt the 'Parental Attitudinal Scale' as part of the screening tool in Non-Governmental Handicap Centre's and Government Rehabilitative Centres. The scale could help in understanding parental attitudes and feelings about their handicapped children and serve as guideline for counseling parents to bring about attitudinal change towards discrimination among disabled children and their education especially the female ones.

\section{References}

Drew, C.J. (2008): Mental Retardation-A Lifecycle approach. Mostle College Publishing, Toronto.

Frude, N. (2002): Understanding Family Problems; A Psychological Approach. John Wiley: Chichester

Federal Republic of Nigeria (2004): National Policy on Education (4th Edition); The Federal Ministry of Education. Abuja.

Kanner, L. (1964): History of the Care and Study of the Mentally Retarded. Thomas Publisher: Springfield, Illinois.

Kroese, B.S (2008): Social Support Network and Psychological well-being of Mothers with Intellectual disabilities. Journal of Applied Research in Intellectual disabilities.15 (4), 324-340.

Kurian, T. (2008): A survey of Parental Attitudes towards their hard of hearing children; Journal of All India Institute of Speech and Hearing. 9,1-8.

McGaw, S. (2002): The Effect of Group Intervention on the Relationships of Parents with Intellectual Disabilities. Journal of Applied Research in Intellectual Disabilities, 15(4), 354-366.

Minuchin, S. (1998): Psychosomatic Families; Harvard University Press, Cambridge.

Nabuzoka, D. \& Smith, P.K (2003): Sociometric Status and Social Behavior of Children with and Without Learning Difficulties . Journal of Child Psychology and psychiatry, 14(8), 1435-1448.

Perosa, L.M (1982): Structural Interaction Pattern in Families with learning disabled children family Therapy. 9(2), 175-187. 